OPEN ACCESS

Edited by:

Sara Cadavid,

Rosario University, Colombia

Reviewed by:

Olivier Dodier

Université de Nantes, France

Erik Mac Giolla,

University of Gothenburg, Sweden

*Correspondence:

Amelia Courtney Hritz ach254@cornell.edu

${ }^{\dagger}$ Present address:

Amelia Courtney Hritz,

Shapiro Arato Bach LLP, New York,

NY, United States

Specialty section:

This article was submitted to

Cognitive Science,

a section of the journal

Frontiers in Psychology

Received: 06 April 2021

Accepted: 18 August 2021

Published: 23 September 2021

Citation:

Hritz AC and Ceci SJ (2021) Lie for

Me: Developmental Trends in

Acquiescing to a Blatantly False

Statement.

Front. Psychol. 12:691276.

doi: 10.3389/fpsyg.2021.691276

\section{Lie for Me: Developmental Trends in Acquiescing to a Blatantly False Statement}

\author{
Amelia Courtney Hritz ${ }^{* \dagger}$ and Stephen J. Ceci \\ Department of Psychology, Cornell University, Ithaca, NY, United States
}

A pair of studies demonstrates that simply asking children to make a blatantly false accusation in the guise of helping others can result in both immediate and long-term false claims. In the pilot study, the initial willingness to make a blatantly false statement was associated with some children making false statements a week later despite being told that the first interviewer had made mistakes during the initial interview. On a positive note, the majority of participants accurately stated that they did not have first-hand knowledge of their accusation's accuracy. Across both studies, the rate of false accusation rates was high. The main experiment demonstrated that children who were young, possessed the lowest verbal intelligence or who were from the lowest SES homes made the most accusations. These findings illustrate not only the dangers of encouraging children to make false statements, but the ease and durability of making such false statements.

Keywords: interview, false memory, witness, age, compliance, lie

\section{INTRODUCTION}

A large corpus of research has documented the deleterious effects of various interviewing behaviors. This research has demonstrated that children's report accuracy can be reduced as a result of providing either pre- or post-event misinformation. Pre-event misinformation that can damage children's report accuracy includes the provision of false stereotypes, rumors, inaccurate co-witness information, and unfulfilled expectations (e.g., Pynoos and Nader, 1989; Leichtman and Ceci, 1995; Garven et al., 2000; Principe et al., 2006). Similarly, post-event misinformation that can damage children's report accuracy includes misleading suggestions provided by an interviewer (e.g., Poole and Lindsay, 1995; Cassel et al., 1996), visualization inductions (Ceci et al., 1994), reinforcement (Garven et al., 1998, 2000), imagination-inflation techniques, and leading questions (Ceci, 1994; Ceci and Bruck, 1998; Bruck et al., 2006; Howe et al., 2009; Otgaar et al., 2016, 2017).

In addition to these suggestive techniques associated with report inaccuracy, a growing body of research has documented developmental trends in children's willingness to mislead interviewers. Talwar, Lee, and their associates have produced a large body of research on the developmental course and cognitive and social correlates of lie-telling (e.g., Talwar and Lee, 2002a,b, 2008; Talwar et al., 2007a,b; Talwar and Crossman, 2011; Evans and Lee, 2013). Lies told in the service of achieving selfish ends, such as gaining material rewards or escaping punishment, begin early during the pre-school years and are reduced in magnitude by middle childhood, whereas lies told in the service of socially desirable ends, such as pretending to appreciate an undesirable gift, tend to begin later. Both types of lies 
are associated with cognitive and social factors such as theory of mind, social skills, and parenting (e.g., Clarke-Stewart et al., 2004; Lavoie et al., 2016).

The current study builds on the developmental research on children's report inaccuracy and deception in several ways: first, we examine a context that differs from spontaneous lies generated to serve selfish or prosocial aims, namely, willingness to acquiesce to a blatantly false persuasion request, using a paradigm that has not been used for this purpose previously but which may have practical relevance to legal cases. Second, we are interested in the intersection between lies and false beliefs, asking whether the former can influence the latter as some have opined (e.g., Leichtman and Ceci, 1995; Zaragoza et al., 2001; Otgaar and Baker, 2018). Finally, we include sociodemographic variables that have only rarely been included in the memory development literature, but which theoretical research suggests could be important sources of systematic developmental variability (Bronfenbrenner and Ceci, 1994; Ceci et al., 2010). Very few studies have examined children's acquiescence to a misleading persuasion as a function of parent social class, which Talwar, Lee and their colleagues suggest may moderate children's acquiescence. We also include the role of verbal intelligence as a potential moderator; although it has received some attention (e.g., Roebers and Schneider, 2001; Chae and Ceci, 2005), it has heretofore not been studied in the context of acquiescence to blatantly false persuasion requests. The closest it has come to this context was a study by Clarke-Stewart et al. (2004) that found that 5-year-olds with the highest verbal intelligence were the most resistant to adult attempts at false persuasion.

Children may make statements about events they initially know to be false if the statements are suggested by adults who hold a priori beliefs about their authenticity. Adults may signal their beliefs through methods such as repeating specific misinformation during questioning (e.g., Warren et al., 1991; Leichtman and Ceci, 1995; Poole and Lindsay, 2001; Moore et al., 2018), offering praise, bribes or threats of punishment (Garven et al., 1998; Schreiber et al., 2006), rejecting or ignoring children's denials (White et al., 1997; Garven et al., 1998), and selectively reinforcing their incorrect statements (Zaragoza et al., 2001). Such social pressure can cause a child to make statements that, while consistent with the belief of the interviewer, are inconsistent with the child's actual perceptual experience (for a review see Ceci and Bruck, 1998; Bruck et al., 2006). Even mild forms of suggestion can increase inaccurate reports by children, such as descriptions of events by parents (e.g., Thompson et al., 1997; Poole and Lindsay, 2001), visualization inductions (Ceci et al., 1994) being informed that co-witnesses have made a disclosure (Principe and Ceci, 2002), stereotypes (Leichtman and Ceci, 1995; Moore et al., 2018), or even naturally-occurring conversations with parents and peers (Bruck et al., 1999; Principe and Schindewolf, 2012; Kim et al., 2017).

Once encoded, false memories can lead children to maintain inaccurate reports in later neutral interviews. Efforts to retrieve accurate memories following the creation of false memories-for instance by instructing children to say when they are unsure, or correcting the interviewer when she makes a false suggestionoften will not offset the impact of the false memory (e.g., Poole and Lindsay, 2001; Zaragoza et al., 2001), although there is some evidence that warning children that questions may be tricky does result in a small but significant reduction in errors $(\sim 5 \%)$ to suggestive questions (Warren et al., 1991). Even efforts to talk children out of their false beliefs can be unsuccessful (e.g., Ceci et al., 1994; Ceci, 1995; Leichtman and Ceci, 1995; Kim et al., 2017). And the metacognitive strategies that are useful in rejecting false information-recollection rejection, retrieval editing, and monitoring-are less effective for young children (Brainerd et al., 2008; Moore et al., 2018). These past findings set the stage for the current study by moving the issue from subtle misleading suggestions by an interviewer to blatantly false persuasive statements.

In contrast to the voluminous literature on the effects of suggestive interviews and misinformation [e.g., see integrative reviews by Poole and Lamb (1998), Quas et al. (2000), Otgaar et al. (2014), Schneider (2015), Goodman et al. (2017)] as well as on factors associated with developmental trends in lie-telling (e.g., the work of Talwar, Crossman, Lee and their colleagues), we were interested in what would happen if instead of exposing participants to techniques designed to bias their report accuracy-such as suggestive interviews, stereotypes, visual inductions, post-event misinformation, incentives to liean adult blatantly makes a false accusation in the guise of helping others. Hence, in the current research, we were interested in (a) what happens when children are exposed to an adult's blatantly false assertion and they are asked to repeat it and sign their agreement with it, an extreme form of forced confabulation. Related questions include: (b) will children acquiesce and sign an adult's blatantly erroneous statement, and if so, (c) will they subsequently incorporate it into their long-term reports to a neutral interviewer who instructs them to ignore the blatantly incorrect prior interviewer, and (d) what, if any, developmental trends or social or cognitive correlates will influence their performance?

Thus, in the following experiments we sought to determine whether will children make a blatantly false accusation merely because someone asks them to do so to help unnamed others? And, if so, will children later maintain the false accusation when interviewed outside the presence of the previously biased adult by an unbiased person who urges them to report only what they actually experienced, not what the blatantly biased adult told them? We hypothesized that (a) children will be more likely to make a false accusation in an initial interview if they are blatantly asked to do so in service of helping unnamed others (children who attended a different school, they were told), and (b) they will subsequently maintain this false assertion with a neutral interviewer, especially if they are younger and more suggestible and/or have lower verbal intelligence. These were all a priori expectations that we made based on previous research showing that the mechanisms that could drive this effect are unfolding rapidly over early and middle childhood as we briefly describe below. We undertook a mini test of the planned procedure to make sure it would work with the intended age groups in a largerscale experiment with controls; this mini test gave us confidence 
that the youngest children understood the procedure (e.g., the wording to request them to endorse a blatantly false statement) although it also led to changes in the procedure.

There are empirical and theoretical reasons for positing that the period between early and middle childhood is one of rapid development of the factors of interest in the current study. A confluence of cognitive, social, and neurobiological developments unfold between early and middle childhood that are relevant to understanding the effect of exposure to blatantly false statements on later report accuracy. Specifically, social developments are occurring between the ages of 4 and 10 that could be relevant in the context of children's compliance with false persuasions by an adult. As noted, younger children are more influenced by a powerful adult authority figure than are older children (e.g., Ceci et al., 1987); preschoolers are more inclined to conform to false persuasion than are adults (ClarkeStewart et al., 2004) but older children are actually less likely to conform than adults, thus a U-shaped function (Kim et al., 2017). There are also improvements in source monitoring over early and middle childhood (e.g., Poole and Lindsay, 1995). Quas et al. (2000) reported that younger children had significantly more difficulty sourcing their memories than did older children, a skill that is relevant in the present study in which children are asked to describe an event to a neutral interviewer after receiving a false persuasion request from a prior interviewer, thus creating a potential source misattribution. On the other hand, in their extensive review, Bruck and Melnyk (2004) did not find correlations between source monitoring and suggestibilityproneness even though both displayed normative developmental trends (Quas et al., 2000); the majority of the studies Bruck and Melnyk reviewed showed no relationship between individual differences in source monitoring and suggestibility. Young children also lack metamemorial insights that limit their recollective accuracy, as shown in Wellman's (1978) classic work, when they were more impeded by misinformation (for review see Ceci and Bruck, 1993). Preschool-aged children also lack strategy knowledge, such as elaborative rehearsal (Ornstein, 1978), and they have relatively undeveloped retrieval-time editing (Brainerd and Reyna, 2001), and second-order theory of mind in which participants must identify a third person's beliefs based on what the second person believes, which does not asymptote before at least age 8 (e.g., Arslan et al., 2012; Hiatt and Trafton, 2015). Although the right dorsolateral region of the pre-frontal cortex continues to develop into young adulthood, it is disproportionately undeveloped among preschoolers (Giedd et al., 1999; Gogtay et al., 2004), limiting their ability to inhibit, track, and monitor the contents of their memory (Ceci et al., 2010). In short, this confluence of developments in cognitive (memory, strategy use, theory of mind), social (conformity, deferral of memory to those of perceived as more authoritative), and neuromaturational (tracking, monitoring) mechanisms converge to anticipate that the period between early and middle childhood is one of heightened relevance for the present hypotheses. It was for this reason that we focused on this transition.

The departure point for the present set of experiments is that unlike studies that employed techniques known to bias report accuracy, in the present study none of the documented explicit or implicit suggestive techniques that damage report accuracy were employed-i.e., there were no post-event suggestions, misleading questions, visually-guided inductions, stereotypes, reinforcements, or automatic semantic associations that have previously been shown to cause children's reporting errors (Bruck and Ceci, 1999; Ceci and Friedman, 2000; Ceci and Bruck, 2006). Instead, the present approach seems straightforward and could have implications for disclosures that come about in the context of one adult urging a child to acquiesce to a false statement about another. For example, in an acrimonious custody dispute a child, upon the request of one parent, may initially repeat a blatantly false statement made by one parent about another parent, and over time elaborate the statement, as has been suggested by some to occur in actual cases (see Bruck and Ceci, 2013). What effect might repeating a blatantly false assertion have on a children's later reports to a neutral interviewer who encourages report accuracy?

\section{PILOT STUDY}

Based on insights from a demonstration study of 16 children who watched clowns perform magic tricks, we designed a somewhat larger pilot study in which children watched a chemist perform "magic tricks" with chemistry. An interviewer later asked children to tell them that the chemist had broken a test tube during the demonstration. At no time did the chemist break any of the test tubes in the magic show and children were not shown any evidence of a broken test tube during either the event itself or during either of the two interviews that followed it. Thus, the children in this experiment were not provided with any evidence that the chemist broke a test tube during the show they watched; the only basis for claiming he did so was an assertion by the initial interviewer that others who attended a different camp session had told her he broke a test tube at their session.

\section{Methods \\ Participants}

Data for this pilot study were collected on 54 children attending a summer camp hosted by a children's science museum. These participants ranged in age from 6 to 11 years old $(M=8.52, S D$ $=1.42$ ); $41 \%$ were male. Ideally, we planned to extend this age range downward to capture the entire early childhood-middle childhood span that has been implicated in the developmental research reviewed earlier.

\section{Procedure}

The measures and procedure employed in this study were approved by the university's institutional review board (1303003677 “Children's False Accusations without Suggestive Questioning”). Participants watched a chemist perform 12 different magic tricks including a trick where she mixed acids, bases, and indicators in a test tube to create a rainbow tube. Several days later $(M=2.02$ days, $S D=0.94)$, participants were interviewed individually by an unfamiliar female adult. This interviewer solicited a free narrative about what transpired during the magic show, followed by two directive questions 
about the magic show: "Do you remember seeing a test tube?"; "Did the chemist do any tricks with the test tube?" (Answers to these questions and the child's free narrative served as a baseline to judge later responses that followed this interviewer's request to endorse her blatant lie). Next, the interviewer informed the child that she had heard from children who attended another chemistry show that the chemist broke his test tube during their show. Then she blatantly asked the child to say the chemist broke a test tube during the magic show they saw (even though he had not). Specifically, she said: "I need your help so he doesn't accidently do this again, or other children will not get to see the magic show. Can you help me? Can you tell me the chemist broke the test tube so I can make sure he doesn't do this again?" The direct request for affirmation was done to resemble a situation in which an adult asks a child to affirm a non-event, one they could not have witnessed but which they might assume the adult had witnessed and needed their assent for prosocial reasons (allow future children to see the show). After the child answered, the interviewer thanked the child and offered stickers.

Approximately 1 week later $(M=7.56$ days, $S D=6.38)$, a neutral interview took place during which an unfamiliar female adult explained that the previous interviewer had made mistakes when talking to children about the magic show, and she wanted the child to report only what they actually saw in the magic show rather than what the previous interviewer told them. Following these instructions from this neutral interviewer, she asked the child if the chemist accidentally broke his test tube. If the child said yes, the interviewer asked if they had seen it happen with their own eyes. Following this neutral interview, children completed intelligence and suggestibility measures.

In light of the literature on verbal ability and suggestibility, we administered the vocabulary subset of the Wechsler Abbreviated Scale of Intelligence (Wechsler, 1999) to examine if a g-loaded measure of children's verbal intelligence predicted responses during the first and second interview. The vocabulary scaled scores from the Wechsler series of intelligence tests were collected as a rough measure of general intelligence, given its very high saturation on the general intelligence factor, g (Flynn, 2007; Nisbett, 2009). Raw scores on the vocabulary subset of the Wechsler Abbreviated Scale of Intelligence were calculated based on the general scoring principles (Wechsler, 1999). These raw scores were converted to T-scores, which are age-corrected (thus removing any correlation with chronological age) and have a wide range (Wechsler, 1999). Results indicated that intelligence was normally distributed $(M=63.53, S D=11.44, n=53)$ with negative skew.

We administered the Video Suggestibility Scale for Children (VSSC) to discover whether suggestibility predicted responses during the first and second interview. The VSSC produces two parameters of suggestibility-proneness: yield (succumbing to erroneous statements) and shift (changing originally correct answers to false answers in response to negative feedback) (Scullin and Ceci, 2001; Scullin et al., 2002). Results did not differ when the "yield" and "shift" measures from the VSSC were examined separately, and therefore the combined parameter scores were used for the analysis. Scores on the VSSC were normally distributed with a slight positive skew $(M=9.6, S D=$ $4.35, n=52)$.

We found no correlation among our individual difference measures: verbal intelligence and suggestibility were not correlated, and suggestibility was also not correlated with age.

\section{Results}

Most participants were willing to accuse the chemist of breaking the test tube, even though they had not witnessed it and were not presented with any physical evidence of a broken test tube. When blatantly asked to make a false statement, 34 out of 54 children (63\%), asserted that the chemist broke the test tube. Importantly, no child made such false allegations spontaneously during their prior free narrative; it was only done in response to the subsequent blatant request from the interviewer. One week later after being told the initial interviewer made mistakes and got children to make mistakes about what happened during the magic show, most children recanted. Only 13 of the 34 children who had previously asserted the chemist broke the test tube maintained their false accusation. All but two of the children who asserted the accusation during the second interview had also made the assertion in the first interview. These children who made false accusations in both interviews were $32 \%$ of the 34 people who made the accusation in the first interview and $20 \%$ of the total original sample of 54. In addition, five children asserted that they saw the chemist break the test tube with their own eyes. This represented $16 \%$ of the 34 who made the accusation and $9 \%$ of the original 54 .

In sum, a fraction of the participants who watched the chemist do a magic show went along with the initial interviewer's blatant request to affirm her false allegation and many subsequently maintained this false allegation with some claiming to have witnessed it with their own eyes despite no suggestive techniques being employed during the second interview (i.e., there was no provision of erroneous post-event information, misleading questions, imagery inductions, requests to speculate, clumsy stereotypes, forced confabulation questions, etc.). In contrast to the children who went along with the first interviewer's blatant request for a false affirmation, none of the 54 children had made such false allegations spontaneously in their free narratives of what occurred before the interviewer requested the child make a false affirmation. Thus, the damage to children's report accuracy was the result of children assenting to the initial interviewer's assertion, a small fraction of whom subsequently claimed when speaking with a neutral interviewer a week later not only that it occurred but to have witnessed it with their own eyes.

We next compared the children who made a false accusation by age, verbal intelligence, and suggestibility-proneness. Results are displayed in Table 1. As we expected, the youngest children appeared to make most of the false allegations. Because it is possible that with more participants, age would emerge as a significant predictor, we tested this in the main experiment, using a predetermined sample size that possessed ample power to detect differences of the observed magnitude. Similarly, as noted, ultimately a total of five children in this Pilot Study who watched the chemistry show said they saw with their own eyes the chemist 
TABLE 1 | Pilot study: average age, intelligence, and suggestibility by whether they made an accusation during the first interview, second interview, or both.

\begin{tabular}{lccc}
\hline & Two accusations & T 1 accusation only & No accusation \\
\hline Age & $7.81(1.09)$ & $8.76(1.59)$ & $8.66(1.13)$ \\
Intelligence & $62.20(6.84)$ & $64.05(11.80)$ & $63.6(14.1)^{\mathrm{a}}$ \\
Suggestibility & $9.82(5.17)$ & $10.00(4.21)^{\mathrm{a}}$ & $9.06(4.30)$ \\
$N$ & 11 & 22 & 18
\end{tabular}

Values displayed are means (standard deviations in parentheses). Two participants made an accusation in the second interview but not the first, due to the small number they are excluded from the table. ${ }^{a} 1-2$ participants missing scale data.

break the test tube, despite being told by the neutral interviewer that the initial interviewer had caused children to make mistakes and that they should only report what they actually witnessed rather than what the prior interviewer may have told them. All five of these children were 8 years old and younger. Even with the small sample size in this pilot, this age difference was reliable, $t(51)=2.02, p<0.05$, Hedges' $g=0.95$ (large effect). Further comparisons of these five participants did not lead to additional significant results, which could be due to the small sample size.

We did not notice trends when we compared children who made a false accusation by verbal intelligence or suggestibility. Follow-up work with larger and more diverse (in terms of verbal intelligence) samples was conducted in the following main experiment to provide a more robust test of these findings.

\section{MAIN EXPERIMENT}

The data and the findings from pilot study revealed a number of interesting results despite the small sample size. In view of these results, the main experiment was a modification designed to broaden the context by substituting a more active role for the child than was the case in the pilot study where the child passively observed a magic show, and also to include another dependent variable: parent socio-economic status (Talwar et al., 2017). In this experiment children were once again asked by an interviewer to agree with a blatantly false assertion but in a less passive context from the one used in the pilot study. Because of the narrow age differences in the pilot study, this experiment was designed with finer age gradations to shed light on developmental vs. reverse developmental effects (e.g., Kim et al., 2017). Once again, vocabulary scaled scores from the Wechsler series of intelligence tests were collected as a rough measure of general intelligence, g (Flynn, 2007; Nisbett, 2009). Finally, we endeavored to recruit a broad range of SES given that compliance with adult authority figures may be related to parent educational attainment as well as suggestibility (Chae et al., 2016).

\section{Method \\ Participants}

Children were recruited through schools, preschools, and a university-run summer camp. One hundred and seventy-one children and adolescents participated, 434 -year-olds (23 females; $M=50.40$ months, $S D=2.53$ ), and 446 -year-olds (25 females;
$M=73.70$ months, $S D=3.86), 448$-year-olds (22 females; $M=$ 99.09 months, $S D=5.02$ ), and 4412 -year-olds ( 19 females; $M=$ 151.27 months, $S D=6.27$ ).

\section{Procedure}

This experiment involved one male and one female research assistant. Children were brought into a testing room and greeted by an opposite-sex research assistant. The youngest children were escorted by a parent or guardian and the older children were escorted by a teacher's aide or a camp counselor. The oppositesex assistant provided crayons and a coloring book for the child to play with for $\sim 10 \mathrm{~min}$. Toys were displayed prominently on the table, as well as several items of clothing, including a straw hat. After $\sim 10 \mathrm{~min}$, a same-sex research assistant entered the room and was introduced to the child as Jenn or John by the opposite-sex assistant who then departed. To avoid crosssex confounds, all final interviews were conducted by samesexed research assistants. After entering the room, the same-sex assistant engaged the child in actively playing a couple rounds of Simon Says. During this game Jenn or John instructed the child "Simon Says [John/Jenn] put on a straw hat," which the samesex assistant donned; they went through five such actions. After playing this game, the original opposite-sex assistant returned to the room and the same-sex assistant departed. After several minutes of amiable interaction with the child, the opposite-sex research assistant asked the child two memory questions related to real and suggested actions in the Simon Says game ("Do you remember the name of the person who played Simon Says with you?," "Do you remember what Simon Says told him (or her) to do with the straw hat?"). Next, this opposite-sex assistant made two blatantly false assertions about events: the child was told that John (or Jenn) had broken a non-present cell phone and asked the child to say that they saw this happen. Following their response, they were presented with a typewritten document and asked to make a mark to indicate if they saw John (or Jenn) break the cell phone. Then they were told that John (or Jenn) ripped a colored drawing and they were asked to make a mark to indicate that they observed John (or Jenn) rip it. In reality, John (or Jenn) did neither thing (Older participants were asked to sign their name on a line indicating they saw John (or Jenn) rip the drawing and break the cell phone; pre-school-aged children were shown two blank spaces on the sheet where they were asked to make crayon marks to indicate that they saw John (or Jenn) damage each of these items, if they agreed that this happened).

\section{Individual Differences}

To measure verbal intelligence, raw scores on the vocabulary subtest of the Wechsler Preschool and Primary Scale of Intelligence (for the youngest age group) and the Wechsler Intelligence scale for Children-IV (for the three older groups) were converted to scaled scores with a mean of 10 and a standard deviation of 3 based on national norms by age. As was true in the pilot study, the sample was skewed slightly above the national average, with a mean of 11.11, and standard deviation of 2.52.

Parent educational attainment is reported in Table 2. Parent SES may moderate the effect of parenting practices on children's willingness to lie (Talwar et al., 2017) and has been tied to report 
TABLE 2 | Parent education of participants.

\begin{tabular}{lcc}
\hline & Parent 1 & Parent 2 \\
\hline Some high school or less & 1 & 0 \\
High school diploma/GED & 22 & 10 \\
Some college & 35 & 23 \\
College degree & 46 & 51 \\
Some graduate school & 48 & 58 \\
Graduate degree & 22 & 28 \\
Unreported & 1 & 5 \\
\hline
\end{tabular}

TABLE 3 | Descriptive statistics by age group.

\begin{tabular}{lcccc}
\hline & $\mathbf{4}$ year olds & $\mathbf{6}$ year olds & $\mathbf{8}$ year olds & $\mathbf{1 2}$ year olds \\
\hline Intelligence & $10.98(3.01)$ & $11.18(2.58)$ & $11.23(2.22)$ & $11.05(2.26)$ \\
Parent Education & $4.19(1.33)$ & $4.32(1.08)$ & $4.09(1.04)$ & $4.19(0.96)$ \\
Accuracy & & & & \\
One correct & $22(51 \%)$ & $16(36 \%)$ & $12(27 \%)$ & $18(41 \%)$ \\
Two correct & $17(40 \%)$ & $25(57 \%)$ & $29(66 \%)$ & $23(52 \%)$ \\
$N$ & 43 & 44 & 44 & 44 \\
\hline
\end{tabular}

For intelligence, parent education and accuracy, values are mean (standard deviation), all other values are sample size. Parent education is coded on a six-point scale and averaged across parents: 1, did not complete high school; 2, high school graduate; 3, some college attendance; 4, college completion; 5, some post-baccalaureate coursework; 6, PhD or professional degree.

accuracy and suggestibility (e.g., Chae et al., 2016). After coding parent education on a six-point scale and averaging across both parents, parent education was strongly correlated with children's verbal intelligence scaled scores, $r(173)=0.37, p<0.001$.

Participants were asked two questions about salient details in the Simon Says game to gauge how well they attended to it. The questions probed the name of the assistant with whom they played Simon Says (Jenn/John) and what was placed on their partner's head (a straw hat). Based on the accuracy of their answers, they were assigned values of 0,1 , or 2. Thirteen participants answered both questions incorrectly (7\%), 68 answered one correctly (39\%), and 94 answered both correctly (54\%).

For each age group descriptive information on the individual difference variables is displayed in Table 3.

\section{Results}

One-hundred-forty-five participants claimed to have witnessed at least one false event, and 66 participants claimed to have witnessed both false events. A logistic regression model was estimated to predict which children made a false assertion as a function of age, verbal intelligence, and parent education. We mean-centered age, standardized intelligence, and meancentered the average parent education. Table 4 shows the results of the regression. As can be seen, age and parent education were significant predictors for making at least one false assertion. Younger children and children whose parents had less education were more likely to make at least one false assertion. We estimated a $41 \%$ increase in the odds of making a false accusation for a 1-year decrease in age.

Post-hoc analysis further confirmed the strong relationship between age and making false assertions. When we substituted the continuous age variable with the age group variable in the logistic regression, keeping the other predictor variables the same, and ran pairwise comparisons, the 12-year-olds were significantly less likely to make a false assertion compared to all other age groups. More specifically, compared to 12year-olds, the odds of making a false assertion were 14.35 times higher for 4-year-olds, 12.29 times higher for 6-yearolds, and 5.13 times higher for 8-year-olds ( $p$ 's $=0.002,0.003$, 0.05 , respectively). Thus, like the pilot study, this study also documented age differences.

There was a similarly strong relationship between parent education and false assertions. As displayed in Table 4, we estimated the odds of signing a false statement were 4.89 times higher for each unit decrease in parent education. In fact, all of the children who refrained from signing either of the false statements had parents with at least a baccalaureate degree. Of the children whose mothers did not have a college degree, $66 \%$ signed both false statements (compared to $33 \%$ in the group whose mothers had a college degree and $17 \%$ in the group with mothers with post baccalaureate education). A similar trend was found with father's education.

Intelligence was not a significant predictor, however, as noted, it was significantly correlated with parent education. When parent education was omitted from the regression, intelligence was significant, $p=0.05$.

We noticed that there may be a relationship between accuracy and making a false assertion: of the 13 participants who answered both salient questions incorrectly, all claimed to have witnessed at least one false event and 8 of 13 claimed to have witnessed both $(62 \%)$. In case the 13 participants who answered both questions about salient details incorrectly were not sufficiently paying attention, we reran the regression after omitting their responses and results were not significantly different: age and parent education remained significant predictors of making false assertions (both $p s<0.001$ ).

In addition, we ran a logistic regression comparing individuals who made both false assertions to individuals who made one or zero false assertions. Again, in this regression age and parent education were significant predictors (both $p s<0.001$ ).

\section{DISCUSSION}

In the pilot study a sizable portion of children complied with an adult's request to make a blatantly false accusation even though they lacked first-hand knowledge of the alleged infraction. On the other hand, most children who made these false accusations did accurately disclose the truth in a subsequent neutral interview after the interviewer gave them releasing instructions ("The person who talked to you before made a lot of mistakes and got children to make mistakes .... Please tell me only what you actually saw, not what someone told you."). And even when they complied with the blatant request to make a false statement 
TABLE 4 | Logistic regression predicting signing at least one false statement.

\begin{tabular}{|c|c|c|c|c|c|}
\hline & $B$ & SE & $95 \% \mathrm{Cl}$ & Odds & Odds $95 \% \mathrm{Cl}$ \\
\hline Intercept & $-2.59^{\star \star \star}$ & 0.40 & $-3.48,1.89$ & 0.75 & $0.03,0.15$ \\
\hline Age & $0.34^{\star \star \star}$ & 0.08 & $0.19,0.51$ & 1.41 & $1.21,1.67$ \\
\hline Intelligence & 0.22 & 0.29 & $-0.33,0.80$ & 1.25 & $0.72,2.23$ \\
\hline Parent's education & $1.59^{\star \star \star}$ & 0.37 & $0.92,2.39$ & 4.89 & $2.51,10.90$ \\
\hline
\end{tabular}

${ }^{\star * \star} p<0.001$.

and maintained this falsehood when subsequently interviewed by a neutral interviewer, most of these children did not claim to have seen it with their own eyes. In sum, these findings demonstrate that under conditions in which the child is only subjected to a single blatant request for false information, in later interviews a small number of the young children may purport to remember the accusation and misattribute its source to personal experience observing the infraction rather than to the blatantly false statement by the initial interviewer who asked them to claim they actually observed it.

After the neutral interviewer informed children that the prior interviewer had made mistakes and misled children, not all children accurately disclosed that they had not observed the infraction. It is possible that children's initial compliance may have created false memories, retrieval competitions, or source misattributions in some of the youngest children who claimed to have seen the infraction with their own eyes despite being given "release" instructions by the neutral interviewer. Such release instructions should, if anything, have motivated them to retract their former false assertion if they were aware of its falsity. Of course, this is speculative as we have no direct test of the hypothesis that the initial compliance request actually distorted memory as opposed to other possibilities such as children's loyalty to, or even fear of, the adult in the first session, could plausibly lead to them to continuing lying in the follow-up interview. Future research will be needed to test this.

In contrast to reversed developmental trends in which younger children are more resistant to spontaneous false memory due to their less developed semantic associative networks (e.g., Brainerd et al., 2010; Brainerd and Reyna, 2012; Otgaar et al., 2016; Kim et al., 2017), in both the pilot and main study, false assertions were more likely among the youngest children. This developmental finding is consistent with well-documented age trends in source misattributions which routinely document that younger children have greater difficulty separating various sources or inputs into their memories (e.g., Ceci et al., 1994; Quas et al., 2000; Goodman et al., 2017). This literature suggests that children who make source misattributions genuinely come to believe in the veracity of their misattributions and "generally were not able to report that they had been asked about these events in prior interviews" (Quas et al., 2000, p. 218).

In the main study, false assertions were found to occur disproportionately more often among children who had the least educated parents. Relatively little research has examined children's acquiescence to misleading suggestions as a function of socioeconomic and intellectual factors. In the present study, a proxy for parent social class proved to exert a powerful influence. In light of this, one wonders whether prior findings in the developmental literature might be qualified if future researchers were to replicate former designs but include a socioeconomic measure. The role of verbal intelligence has received some attention (e.g., Roebers and Schneider, 2001; Chae and Ceci, 2005). This literature suggests that children with higher verbal intelligence provide more accurate recall and children with very low intelligence can be more suggestible in response to misleading questions. In our study, intelligence, which was significantly correlated with parent education, did not uniquely predict making a false assertion in the context of conformity to blatant lies.

Taken together, the findings from these experiments have implications for cases in which adults articulate biases during conversations with children. The influence of the interviewer can lead some children to make accusations that they initially know are false. In itself, this is hardly a new finding, as decades of deception research have documented that children will lie in response to various incentives (e.g., Talwar et al., 2011; Wyman et al., 2016). However, the present findings demonstrate that this is more strongly observed among the youngest participants from the lowest educated families.

\section{Caveats and Limitations}

The results of the pilot study and main experiment are limited in their forensic implications because we refrained from creating the stress associated with an actual forensic interview in which children: (a) usually know the individual they are accusing, (b) understand that their answers may influence others' opinion of this individual, and (c) are cognizant that this individual could face adverse consequences as a result of their statement. Ethical considerations preclude us from making children feel seriously uncomfortable or protective of loved ones. Thus, the children in these experiments were told that it was probably an accident that the item was broken, and that their help was needed to make sure this did not happen again so that children in another school could enjoy the use of the item. This was done to minimize stress but at the same time it deviates from legal contexts where stress is inherent, thus limiting its practical import.

Furthermore, there were no negative consequences associated with making a false accusation. There was also far less pressure on the children to make false accusations than may inhere in child abuse cases in which multiple suggestive methods might be used in interviews, such as introduction of new suggestive information, positive reinforcement, interviewer's expression of 
disbelief when a child fails to disclose, conformity pressure, and invitations to pretend or speculate (e.g., Garven et al., 1998; Schreiber et al., 2006; Bruck and Ceci, 2013). If in real cases interviewers with biases exerted more pressure and used more suggestions than was done in the current study, the deleterious consequences could be even greater than what were observed under these less intensive circumstances. Thus, even though a substantial fraction of the children in these experiments affirmed the false statement and maintained this affirmation over time, this might have been elevated by increasing the intensity and number of requests.

In addition, the present experiments, although careful to include variables that have often been missing from past studies (socioeconomic status, verbal intelligence), nevertheless did not examine other potentially important individual differences that could be instrumental. Recently, a number of researchers have begun to examine such factors as child and parental attachment status as it relates to suggestibility (Chae et al., 2014, 2018), children's frontal neurological status (Poole et al., 2014), children's social skills (Lavoie et al., 2016), and parental rearing styles as they relate to children's compliance with a false report (Kim et al., 2017). It would be interesting for future work to add such variables to the study of blatantly false statements.

Future research will have to chart the boundary conditions of this effect, although some experimental evidence indicates that children's suggestibility is exhibited even under conditions of stressful physical experience such as during painful medical procedures (e.g., Bruck et al., 1995), and case studies of contested custody are rife with analogs of the present procedure. For example, Bruck and Ceci (2013) describe a custody case that progressed into a series of accusations of sexual abuse by the father of two preschool-aged daughters. The children likely overheard claims made by their mother and repeated statements to a counselor such as "Mommy says Daddy is mean." The

\section{REFERENCES}

Arslan, B., Hohenberger, A., and Verbrugge, R. (2012). "The development of second-order social cognition and its relation with complex language understanding and working memory," in Proceedings of the 34th Annual Conference of the Cognitive Science Society (Austin, TX), 1290-1295.

Brainerd, C., Reyna, V., Wright, A. H., and Mojardin, R. (2008). Recollection rejection: false memory editing in children and adults. Psychol. Rev. 110, 762-784. doi: 10.1037/0033-295X.110.4.762

Brainerd, C. J., Holliday, R. E., Reyna, V. F., Yang, Y., and Toglia, M. P. (2010). Developmental reversals in false memory: Effects of emotional valence and arousal. J. Exp. Child Psychol. 107, 137-154. doi: 10.1016/j.jecp.2010. 04.013

Brainerd, C. J., and Reyna, V. F. (2001). Fuzzy-trace theory: dual processes in memory, reasoning, and cognitive neuroscience. Adv. Child Dev. Behav. 28, 41-100. doi: 10.1016/S0065-2407(02)80062-3

Brainerd, C. J., and Reyna, V. F. (2012). Reliability of children's testimony in the era of developmental reversals. Dev. Rev. 32, 224-267. doi: 10.1016/j.dr.2012.06.008

Bronfenbrenner, U., and Ceci, S. J. (1994). Nature-nurture in developmental perspective: a bioecological theory. Psychol. Rev. 101, 568-586. doi: 10.1037/0033-295X.101. 4.568

Bruck, M., and Ceci, S. J. (1999). The suggestibility of children's memory. Ann. Rev. Psychol. 50, 419-439. doi: 10.1146/annurev.psych.50.1.419 present findings suggest that initially agreeing with an adult's request to affirm such assertions may result in some children later repeating it to a neutral interviewer even if the child initially was aware they had not witnessed them (e.g., in the above case the allegation that the father had harshly snatched a credit card from the mother and cut it half).

\section{DATA AVAILABILITY STATEMENT}

The raw data supporting the conclusions of this article will be made available by the authors, without undue reservation.

\section{ETHICS STATEMENT}

The studies involving human participants were reviewed and approved by IRB, Cornell University. Written informed consent to participate in this study was provided by the participants' legal guardian/next of kin.

\section{AUTHOR CONTRIBUTIONS}

$\mathrm{AH}$ and SC designed the study together. SC drafted the introduction and discussion. $\mathrm{AH}$ drafted the methods and results. The manuscript has been read and approved by both authors. Once the full manuscript was assembled, both authors contributed to editing and finalizing the manuscript. Both authors contributed to the article and approved the submitted version.

\section{ACKNOWLEDGMENTS}

We thank Caisa Royer, Grace Monks, Victoria Dahl, Logan Kenney, and James Dunlea for collecting and coding data and we are grateful to all the families who participated.

Bruck, M., and Ceci, S. J. (2013). Expert testimony in a child sex abuse case: translating memory development research. Memory 21, 556-565. doi: 10.1080/09658211.2013.769606

Bruck, M., Ceci, S. J., and Francoeur, E. (1999). The accuracy of mothers' memories of conversations with their preschool children. J. Exp. Psychol. 5, 89-106. doi: 10.1037/1076-898X.5.1.89

Bruck, M., Ceci, S. J., Francoeur, E., and Barr, R. (1995). "I hardly cried when I got my shot!": influencing children's reports about a visit to their pediatrician. Child Dev. 66, 193-208. doi: 10.2307/1131200

Bruck, M., Ceci, S. J., and Principe, G. (2006). "The child and the law," in Handbook of Child Psychology: Psychology in Practice, 6th Edn, Vol. 4, eds I. Sigel and K. A. Renninger (NY: Wiley), 776-816.

Bruck, M., and Melnyk, L. (2004). Individual differences in children's suggestibility: a review and synthesis. Appl. Cogn. Psychol. 18, 947-996. doi: 10.1002/acp.1070

Cassel, W. S., Roebers, C. E. M., and Bjorklund, D. F. (1996). Developmental patterns of eyewitness responses to repeated and increasingly suggestive questions. J. Exp. Child Psychol. 61, 116-133. doi: 10.1006/jecp.1996.0008

Ceci, S. J. (1994). "Cognitive and social factors in children's testimony," in Psychology in Litigation and Legislation, eds B. D. Sales and G. R. Vandenbos (Washington, DC: American Psychological Association), 14-54.

Ceci, S. J. (1995). "False beliefs: some developmental and clinical considerations," in Memory Distortion: How Minds, Brains, and Societies Reconstruct the Past, eds D. L. Schacter, J. T. Coyle, G. D. Fischbach, M.-M. Mesulam, and L. E. Sullivan (Cambridge, MA: Harvard University Press), 91-125. 
Ceci, S. J., and Bruck, M. (1993). The suggestibility of the child witness: a historical review and synthesis. Psychol. Bull. 113, 403-439. doi: $10.1037 / 0033-2909.113 .3 .403$

Ceci, S. J., and Bruck, M. (1998). "Children's testimony: applied and basic issues," in The Handbook of Child Psychology, 5th Edn, Vol. 4, eds W. Damon, I. Sigel, and K. A. Renninger (Hoboken NJ: Wiley and Sons Inc), 713-774.

Ceci, S. J., and Bruck, M. (2006). Children's suggestibility: characteristics and mechanisms. Adv. Child Dev. Behav. 34, 247-281. doi: 10.1016/S0065-2407(06)80009-1

Ceci, S. J., Fitneva, S. A., and Williams, W. M. (2010). Representational constraints on the development of memory and metamemory: a developmentalrepresentational-theory. Psychol. Rev. 117, 464-495. doi: 10.1037/a0019067

Ceci, S. J., and Friedman, R. D. (2000). The suggestibility of children: scientific research and legal implications. Cornell Law Rev. 86, 34-108.

Ceci, S. J., Loftus, E. F., Leichtman, M., and Bruck, M. (1994). The possible role of source misattributions in the creation of false beliefs among preschoolers. Int. J. Clin. Exp. Hypnosis 42, 304-320. doi: 10.1080/00207149408409361

Ceci, S. J., Ross, D. F., and Toglia, M. P. (1987). Suggestibility of children's memory: psycholegal implications. J. Exp. Psychol. 116, 38-49. doi: 10.1037/0096-3445.116.1.38

Chae, Y., Goodman, G. S., Larsen, R. P., Augusti, E. M., Alley, D., VanMeenen, K. M., et al. (2014). Children's memory for distressing events: the role of children's and parents' attachment. J. Exp. Child Psychol. 123, 90-111. doi: $10.1016 /$ j.jecp.2014.01.005

Chae, Y., Goodman, M., Goodman, G. S., Troxel, N., McWilliams, K., Thompson, R. A., et al. (2018). How children remember the strange situation: the role of attachment. J. Exp. Child Psychol. 166, 360-379. doi: 10.1016/j.jecp.2017. 09.001

Chae, Y., Kulkofsky, S., Debaran, F. B., Wang, Q., and Hart, S. L. (2016). Low-SES preschool children's eyewitness memory: the role of narrative skill. Behav. Sci. Law 34, 55-73. doi: 10.1002/bsl.2242

Chae, Y. J., and Ceci, S. J. (2005). Individual differences in children's recall and suggestibility: the effect of intelligence, temperament, and self-perceptions. Appl. Cogn. Psychol. 19, 383-407. doi: 10.1002/acp.1094

Clarke-Stewart, K. A., Malloy, L. C., and Allhusen, V. D. (2004). Verbal ability, self-control, and close relationships with parents protect children against misleading suggestions. Appl. Cogn. Psychol. 18, 1037-1058. doi: $10.1002 /$ acp. 1076

Evans, A. D., and Lee, K. (2013). Emergence of lying in very young children. Dev. Psychol. 49, 1958-1963. doi: 10.1037/a0031409

Flynn, J. R. (2007). What is intelligence? NY: Cambridge University Press. doi: $10.1017 /$ СBO 9780511605253

Garven, S., Wood, J. M., Malpas, R. S., and Shaw, J. S. (1998). More than suggestion: The effect of interviewing techniques from the McMartin preschool case. J. Appl. Psychol. 83, 347-359. doi: 10.1037/0021-9010.83.3.347

Garven, S., Wood, J. M., and Malpass, R. (2000). Allegations of wrongdoing: the effects of reinforcement on children's mundane and fantastic claims. J. Appl. Psychol. 85, 38-49. doi: 10.1037/0021-9010.85.1.38

Giedd, J. N., Blumenthal, J., Jeffries, N. O., Castellanos, E. X., Liu, H., Zijdenbos, A., et al. (1999). Brain development during childhood and adolescence: a longitudinal MRI study. Nat. Neurosci. 2, 861-863. doi: 10.1038/ 13158

Gogtay, N., Giedd, J. N., Lusk, L., Hayashi, K., Greenstein, D., Vaituzis, A. C., et al. (2004). Dynamic mapping of human cortical development during childhood through early adulthood. Proc. Natl. Acad. Sci. U. S. A. 101, 8174-8179. doi: 10.1073/pnas.0402680101

Goodman, G. S., Jones, O., and McLeod, C. (2017). Is there a consensus about children's memory and suggestibility? J. Interpers. Violence 32, 926-939. doi: $10.1177 / 0886260516657358$

Hiatt, L. M., and Trafton, J. G. (2015). "Understanding second-order theory of mind," in HRI 2015 Extended Abstracts, ACM 978-1-4503-3318-4/15/03. doi: $10.1145 / 2701973.2702030$

Howe, M. L., Wimmer, M. C., Gagnon, N., and Plumpton, S. (2009). An associative activation theory of children's and adults' memory illusions. J. Mem. Lang. 60, 229-251. doi: 10.1016/j.jml.2008.10.002

Kim, I. K., Kwon, E., and Ceci, S. J. (2017). Developmental Reversals in report conformity: psycho-legal implications. Appl. Cogn. Psychol. 31, 128-138. doi: $10.1002 /$ acp.3309
Lavoie, J., Yachison, S., Crossman, A. M., and Talwar, V. (2016). Polite, instrumental, and dual liars: relation to children's developing social skills and cognitive ability. Int. J. Behav. Dev. 41, 257-264. doi: $10.1177 / 0165025415626518$

Leichtman, M. D., and Ceci, S. J. (1995). The effects of stereotypes and suggestions on preschoolers' reports. Dev. Psychol. 31, 568-578. doi: $10.1037 / 0012-1649.31 .4 .568$

Moore, K. N., Lampinen, J. M., Gallo, D. A., Adams, E. J., and Bridges, A. J. (2018). Children's use of memory editing strategies to reject source misinformation. Child Dev. 89, 219-234. doi: 10.1111/cdev.12716

Nisbett, R. (2009). Intelligence and How to Get It. NY: Norton.

Ornstein, P. A. (ed.). (1978). Memory Development in Children. Hillsdale, NJ: Erlbaum.

Otgaar, H., and Baker, A. (2018). When lying changes memory for the truth. Memory 26, 2-14. doi: 10.1080/09658211.2017.1340286

Otgaar, H., Howe, M. L., Brackmann, N., and van Helvoort, D. H. J. (2017). Eliminating age differences in children's and adults' suggestibility and memory conformity effects. Dev. Psychol. 53, 962-970. doi: 10.1037/dev0000298

Otgaar, H., Howe, M. L., Peters, M., Smeets, T., and Moritz, S. (2014). The production of spontaneous false memories across childhood. J. Exp. Child Psychol. 121, 28-41. doi: 10.1016/j.jecp.2013.11.019

Otgaar, H., Scoboria, A., Howe, M. L., Moldoveanu, G., and Smeets, T. (2016). Challenging memories in children and adults using an imagination inflation procedure. Psychol. Conscious. 3, 270-283. doi: 10.1037/cns00 00087

Poole, D. A., Dickinson, J. J., Brubacher, S. P., Liberty, A. E., and Kaake, A. M. (2014). Deficient cognitive control fuels children's exuberant false allegations. J. Exp. Child Psychol. 118, 101-109. doi: 10.1016/j.jecp.2013.0 8.013

Poole, D. A., and Lamb, M. E. (1998). Investigative Interviews of Children: A Guide for Helping Professionals. Washington, DC: American Psychological Association. doi: 10.1037/10301-000

Poole, D. A., and Lindsay, D. S. (1995). Interviewing preschoolers: effects of nonsuggestive techniques, parental coaching and leading questions on reports of nonexperienced events. J. Exp. Child Psychol. 60, 129-154. doi: $10.1006 /$ jecp. 1995.1035

Poole, D. A., and Lindsay, D. S. (2001). Children's eyewitness reports after exposure to misinformation from parents. J. Exp. Psychol. 7, 27-50. doi: 10.1037/1076-898X.7.1.27

Principe, G., Kanaya, T., Ceci, S. J., and Singh, M. (2006). Believing is seeing: how rumors can engender false memories in Preschoolers. Psychol. Sci. 17, 243-248. doi: $10.1111 / j .1467-9280.2006 .01692 . x$

Principe, G., and Schindewolf, E. (2012). Natural conversations as a source of false memories in children: implications for the testimony of young witnesses. Dev. Rev. 32, 205-223. doi: 10.1016/j.dr.2012.06.003

Principe, G. F., and Ceci, S. J. (2002). "I saw it with my own ears": the effects of peer conversations on preschoolers' reports of nonexperienced events. J. Exp. Child Psychol. 83, 1-25. doi: 10.1016/S0022-0965(02)00120-0

Pynoos, R. S., and Nader, K. (1989). Children's memory and proximity of violence. J. Am. Acad. Child Adolesc. Psychiatry 28, 236-241. doi: 10.1097/00004583-198903000-00015

Quas, J. A., Schaaf, J. M., Alexander, K. W., and Goodman, G. S. (2000). "Do you really remember it happening or do you only remember being asked about it happening?: children's source monitoring in forensic contexts," in Children's Source Monitoring, eds K. Roberts and M. Blades (Mahwah, NJ: Erlbaum Associates), 197-226.

Roebers, C. M., and Schneider, W. (2001). Individual differences in children's eyewitness recall: the influence of intelligence and shyness. Appl. Dev. Sci. 5, 9-20. doi: 10.1207/S1532480XADS0501_2

Schneider, W. (2015). Memory Development From Early Childhood Through Emerging Adulthood. NY: Springer. doi: 10.1007/978-3-319-09611-7

Schreiber, N., Bellah, L. D., Martinez, Y., McLaurin, K. A., Strok, R., Garven, S., et al. (2006). Suggestive interviewing in the McMartin Preschool and Kelly Michaels daycare abuse cases: a case study. Soc. Influence 1, 16-47. doi: 10.1080/15534510500361739

Scullin, M., Kanaya, T., and Ceci, S. J. (2002). Measurement of individual differences in children's suggestibility across situations. J. Exp. Psychol. 8, 233-246. doi: 10.1037/1076-898X.8.4.233 
Scullin, M. H., and Ceci, S. J. (2001). A suggestibility scale for children. Pers. Individ. Dif. 30, 843-856. doi: 10.1016/S0191-8869(00)00077-5

Talwar, V., and Crossman, A. (2011). From little white lies to filthy liars: the evolution of honesty and deception in young children. Adv. Child Dev. Behav. 40, 139-141. doi: 10.1016/B978-0-12-386491-8.00004-9

Talwar, V., Crossman, A., Williams, S., and Muir, S. (2011). Adult detection of children's selfish and polite lies: experience matters. J. Appl. Soc. Psychol. 41, 2837-2857. doi: 10.1111/j.1559-1816.2011.00861.x

Talwar, V., Gordon, H. M., and Lee, K. (2007a). Lying in the elementary school years: verbal deception and its relation to second-order belief understanding. Dev. Psychol. 43, 804-810. doi: 10.1037/0012-1649.43.3.804

Talwar, V., Lavoi, J., Gomez-Garibello, C., and Crossman, A. M. (2017). The influence of social factors on the relation between lie-telling and children's cognitive abilities. J. Exp. Child Psychol. 159, 185-198. doi: 10.1016/j.jecp.2017.02.009

Talwar, V., and Lee, K. (2002a). Emergence of white-lie-telling in children between 3 and 7 years of age. Merrill Palmer Q. 48, 160-181. doi: 10.1353/mpq.2002. 0009

Talwar, V., and Lee, K. (2002b). Development of lying to conceal a transgression: children's control of expressive behavior during verbal deception. Int. J. Behav. Dev. 26, 436-444. doi: 10.1080/016502501430 00373

Talwar, V., and Lee, K. (2008). Social and cognitive correlates of children's lying behavior. Child Dev. 79, 866-881. doi: 10.1111/j.1467-8624.2008.01164.x

Talwar, V., Murphy, S. M., and Lee, K. (2007b). White lie-telling for children in politeness purposes. Int. J. Behav. Dev. 31, 1-11. doi: $10.1177 / 0165025406073530$

Thompson, W. C., Clarke-Stewart, K. A., and Lepore, S. J. (1997). What did the janitor do? Suggestive interviewing and the accuracy of children's accounts. Law Human Behav. 21, 405-426. doi: 10.1023/A:1024859219764

Warren, A. R., Hulse-Trotter, K., and Tubbs, E. (1991). Inducing resistance to suggestibility in children. Law Hum. Behav. 15, 273-285. doi: 10.1007/BF01061713

Wechsler, D. (1999). Wechsler Intelligence Scale for Children-IV. San Antonio, TX: Psychological Corp.
Wellman, H. M. (1978). Knowledge of the interaction of memory variables: a developmental study of metamemory. Dev. Psychol. 14, 24-29. doi: 10.1037/0012-1649.14.1.24

White, T. L., Leichtman, M. D., and Ceci, S. J. (1997). The good, the bad, and the ugly: accuracy, inaccuracy, and elaboration in preschoolers' reports about a past event. Appl. Cogn. Psychol. 11, S37-S54. doi: 10.1002/(SICI)10990720(199712)11:7<S37::AID-ACP546>3.0.CO;2-4

Wyman, J., Foster, I., and Talwar, V. (2016). An experimental analysis of children's ability to provide a false report about a crime. J. Visual. Expe. 111:e53773. doi: $10.3791 / 53773$

Zaragoza, M. S., Payment, K. E., Ackil, J. K., Drivdahl, S. B., and Beck, M. (2001). Interviewing witnesses: forced confabulation and confirmatory feedback increase false memories. Psychol. Sci. 12, 473-477. doi: $10.1111 / 1467-9280.00388$

Conflict of Interest: After the writing of this article but before publication, AH became employed by the law firm Shapiro Arato Bach LLP.

The remaining author declares that the research was conducted in the absence of any commercial or financial relationships that could be construed as a potential conflict of interest.

Publisher's Note: All claims expressed in this article are solely those of the authors and do not necessarily represent those of their affiliated organizations, or those of the publisher, the editors and the reviewers. Any product that may be evaluated in this article, or claim that may be made by its manufacturer, is not guaranteed or endorsed by the publisher.

Copyright $(02021$ Hritz and Ceci. This is an open-access article distributed under the terms of the Creative Commons Attribution License (CC BY). The use, distribution or reproduction in other forums is permitted, provided the original author $(s)$ and the copyright owner(s) are credited and that the original publication in this journal is cited, in accordance with accepted academic practice. No use, distribution or reproduction is permitted which does not comply with these terms. 